\title{
ANALIZANDO EL REGIMEN DE LAS NULIDADES DESDE UN DEFECTO FORMAL (FALTA DE FIRMA EN LA ESCRITURA)
}

\author{
Por Augusto Luis Piccon 1
}

SUMARIO.I. INTRODUCCION. II. DESARROLLO. III. CONCLUSIONES

\section{RESUMEN:}

Este trabajo trata la teoría general de las nulidades, pero se hace una vinculación con lo práctico, con la intención de darle al lector de esta revista algo entretenido. Trata de vincularlo con el trabajo cotidiano del notario, la escritura en su aspecto formal, haciendo hincapié en las soluciones de esos defectos que causan la nulidad.

\section{ABSTRACT}

This paper deals with the general theory of nullities, but a link is made with the practical, with the intention of giving the reader of this magazine something entertaining. It try to link with the daily work of the notary, the deed in its formal aspect, emphasizing the solutions of those defects that cause nullity.

PALABRAS CLAVE: Nulidades. Efectos Jurídicos. Implicancia Notarial.

KEY WORDS: Nullities. Legal Effects. Notarial Implication

\section{Introducción}

Es necesario manejar el tema Nulidad, no solo porque es uno de esos temas bases y transversales a todos los institutos jurídicos, sino porque tiene una relevancia práctica en el diario accionar de cada escribano en su escribanía, donde le cabe aplicar el derecho, subsumir el hecho en la norma, antes que al juez.

Este trabajo trata la teoría general de las nulidades, pero se hace una vinculación con lo práctico, con la intención de darle al lector de esta revista algo entretenido, se trata de vincularlo con el trabajo cotidiano del notario, la escritura en su aspecto formal, haciendo hincapié en las soluciones de esos defectos que causan la nulidad.

Sin embargo, tratamos de tener cuidado en esa cuestión práctica, porque cuando queremos ver la utilidad de todo esto, nuestra mirada no es tan fría, es más interesada. La

1 Profesor en la Carrera de Notarial en Facultad de Derecho de la Universidad Nacional de Córdoba, Profesor Universidad Blas Pascal y Universidad Católica de Córdoba. 
experiencia toma un rol muy importante, pero es necesario que la analicemos como científicos a la luz de los valores que busca el derecho, remontándonos siempre a los principios generales, para dar una solución coherente con todo el sistema. Pese a la contradicción que significa debemos buscar elevarnos a las bases, las que nos van a permitir movernos tranquilos y seguros en el lodo de los problemas concretos.

La idea con este trabajo es analizar todo el régimen de las nulidades en el nuevo Código Civil y Comercial, pero para ello hacerlo desde un caso de nulidad especifica, más precisamente una nulidad formal, la falta de firma "de las partes" en una escritura.

Aquí va entonces, un pequeño trabajo tratando de compatibilizar estas ideas, espero haberlo logrado.

\section{Desarrollo}

\section{Art, 309.- Nulidad. Son nulas las escrituras que no tengan .... la firma .... de las partes,...}

\section{Concepto de Nulidad}

Nada mejor para empezar a hablar de un tema, que ubicarnos en algún lugar desde donde partir, es muy útil para entender cualquier cuestión. Debemos comprender que estamos en el ámbito de la ineficacia, o sea en el estudio de las razonas por las cuales un acto jurídico no produce efectos que le son propios.

La doctrina nos marca que hay dos tipos de ineficacia, "se habla así de ineficacia estructural y de ineficacia funcional. En la ineficacia estructural, la privación de los efectos propios de un acto jurídico se produce por defectos estructurales (se encuentran dentro del negocio) y originarios (existen desde el momento de su celebración).... En la ineficacia funcional, la privación de los efectos propios de un acto jurídico se produce a causa de hechos sobrevenidos a la celebración del negocio y extrínsecos a su estructura. Son supuestos de ineficacia funcional: la rescisión, la revocación y la resolución, en las cuales no está involucrada la validez del acto." ${ }^{2}$ Y por lo tanto el tema que nos ocupa, la nulidad, está relacionado a la ineficacia estructural.

Cuando se la trata de definir, vemos que la doctrina parte en general de establecerla como una sanción, así dice Rivera “La nulidad es una sanción legal que priva a un acto jurídico de sus efectos propios o normales, por adolecer de defectos originarios, orgánicos y esenciales a través de un proceso de impugnación y declaración"3. Malicki le agrega en su definición "con efecto retroactivo y frente a todos (partes y terceros)"

Varios en doctrina discuten el carácter de sanción, porque esto implicaría el "castigo al autor de una infracción a un deber jurídico"s. Esto sería la reacción del ordenamiento legal ante el sujeto que busca infringir la norma. Pero lo cierto es que esta explicación no se corresponde con varios de los casos de nulidad. El mismo Rivera pone de ejemplo el caso del vicio de error no provocado y reconoce que las sanciones son a las personas,

\footnotetext{
2 MALICKI Anahí Comentario, enCódigo Civil y Comercial de la Nación. Dir: Graciela Medina, Julio C. Rivera. Cord: Mariano Esper. Editorial La Ley 2014. "La nulidad es una sanción legal que priva a un acto jurídico de sus efectos propios o normales, con efecto retroactivo y frente a todos (partes y terceros), por adolecer de defectos originarios, estructurales y esenciales a través de un proceso de impugnación y declaración"

3 RIVERA, Julio Cesar, Instituciones de Derecho Civil, Parte General, Ed LexisNexisAbeledoPerrot, 1994 Tomo II, Pag 942.

4 MALICKI Anahí Comentario, enCódigo Civil y Comercial de la Nación. Dir: Graciela Medina, Julio C. Rivera. Cord: Mariano Esper. Editorial La Ley 2014.

5 FALBO, Marcelo N. "Hacia una depuración de la Teoria de las Nulidades" trabajo presentado en la XXVI Jornada Notarial Argentina, celebrada en Córdoba en el año 2002, pág 20.
} 
no a los actos, por eso también dice que "da paso a la sanción", que es la privación de efectos fundada en una ilicitud en sentido amplio.

Puede ser simple hablar de sanción, pero evidentemente, nos da una ida errada para entenderla, y como dice Falbo "en la medida que tengamos una preconcepción errada del instituto, esta se trasladará sobre las conclusiones que se vayan desprendiendo de la posterior investigación"6. "La ausencia de efectos no se producirá como castigo o sanción a la violación de la ley, sino como consecuencia natural de una conducta que no coincide con el supuesto previsto en la norma que asigna los efectos"7. Nos quedaría decir entonces qué es la nulidad para Falbo, para él es "el régimen jurídico que regula los efectos del acto que no ha llegado a conformarse como negocio jurídico perfecto, de acuerdo a los requisitos que la ley establece" ${ }^{\prime \prime}$.

\section{Existencia y nulidad}

Dicen las definiciones de nulidad que los vicios que afectan al acto son "originarios, orgánicos y esenciales" (Rivera), u "originarios, estructurales y esenciales" (Malicki), dejando de lado las primeras dos características, que no hace falta profundizar, puesto que como ya dijimos estar en el ámbito de la ineficacia estructural, damos por sobrentendido que siempre son vicios anteriores o concomitantes al otorgamiento del acto jurídico, y dentro del negocio o acto mismo. El problema está en analizar el carácter de esencial, puesto que muchas veces se establece la invalidez por un defecto que si bien es grave o sumamente grave, no es esencial para la configuración como tal, sino que la ley lo ha establecido como tal, dejando de lado una cuestión ontológica sino más bien valorativa. Por ejemplo los testigos de una escritura pública, no es un requisito exigido por ley como lo era antaño, sino solo para el caso del Testamento, lo que no quiere decir que mañana el legislador piense que no son necesarios para este caso tampoco.

Sin embargo podemos decir que la mayor parte de las veces son esenciales, a la configuración del acto como tal. Podríamos decir que son defectos muy importantes abarcando a los esenciales y a otros, que no lo son pero que son de gravedad, para el fin buscado por la ley.

Esto es una de las diferencias para distinguir la invalidez de la inexistencia, Pero hay otra también sumamente importante.

Como bien dice Zavala "la noción de inexistencia de los actos jurídicos no está subordina a los textos legales, sino que los domina, no constituye una mera clasificación dentro de la teoría de las nulidades o de la ineficacia de los actos jurídicos, se mueve en un plano diferente no delimitado por la ley, ni es una noción legal, sino que es conceptual. La existencia (y su reverso) corresponde al mundo del ser, y no al jurídico del deber ser" y como transcribe en su nota al maestro Nuñez Lagos diremos que "El consentimiento, además de existir, ha de ser apto para la eficacia legal de lo contenido, esto es, ha de ser válido. Positivamente, los conceptos son existencia y validez, negativamente inexistencia

\footnotetext{
6 FALBO, Marcelo N. “Código Civil y Comercial de la Nación” Coordinador Eduardo Gabriel CRUSELLAS, Ed Astrea 2015.

7 FALBO, Marcelo N. "Hacia una depuración de la Teoria de las Nulidades" trabajo presentado en la XXVI Jornada Notarial Argentina, celebrada en Córdoba en el año 2002, pág 20.

8 FALBO, Marcelo N. "Hacia una depuración de la Teoria de las Nulidades" trabajo presentado en la XXVI Jornada Notarial Argentina, celebrada en Córdoba en el año 2002, pág 20.

9 ZAVALA, Gastón Augusto, "Ineficacia y subsanaciones en el documento notarial”, Revista Notarial No943, Pag 758 Año 2002.
} 
y nulidad o invalidez. Existencia e inexistencia pertenecen a la esfera de los hechos, validez y nulidad, a la escala de valores sobre los hechos, a la calificación de esos hechos, al ámbito del derecho"

Ahora si la nulidad o invalidez fueran solo sobre defectos esenciales, coincidiría estrictamente con la teoría de la inexistencia, puesto que hay inexistencia cuando al acto le faltan elementos esenciales para serlo, dice CarminioCastagno que "la ausencia de siquiera de uno de los requisitos "esenciales" de algo, obsta a su concreción (pudiéndose estar ante la "nada" (inexistencia) o un "algo" distinto"10.

\section{Inexistencia y Nulidades implícitas o virtuales}

Sin embargo aunque vemos que la ley establece la invalidez ante la falta o defecto de elementos esenciales del acto jurídico, también a veces no lo hace, y el problema es que hacemos en estos casos. Con la anterior normativa del código, parte de la doctrina acudía a las nulidades virtuales o implícitas, así Rivera nos decía "la sanción de nulidad puede surgir expresa o implícitamente de la ley"111, o sea siempre en base a la ley, con fundamento en el antiguo artículo 18 que disponía que "los actos prohibidos por las leyes son de ningún valor, si la ley no designa otro efecto para el caso de contravención" y ponía como ejemplo, la exigencia de firma como condición esencial en los instrumentos privados del artículo 1012, sin establecer expresamente su nulidad. Justamente ese mismo ejemplo es el que da Carminio Castagno para establecer donde se aplica la teoría de la inexistencia del acto jurídico. Por su parte Falbo entiende que "en la medida en que conceptualizamos al acto nulo ... como el que no llegó a conformarse como negocio jurídico perfecto, por no haberse cumplido con todos los requisitos que la ley establecía en su modelo normativo, entenderemos que necesaria e indefectiblemente en todos los casos la nulidad tiene su origen en la letra de la ley, sin que sea necesario que la norma mencione -de manera expresa- la palabra "nulidad" o "invalidez". En definitiva, la clasificación se limitaba al ámbito académico, sin que de ella pudieran extraerse consecuencias reales prácticas". El problema con este último criterio en lo práctico, sería determinar que elementos constituyen el modelo normativo, que da lugar a que su falta produzca la falta de efectos normales y que elementos no, y si queda restringido a lo esencial, estaría más cerca de la teoría de la inexistencia que de la nulidad.

Hoy no tenemos un art 18 en nuestro código civil, por eso cobra mayor relevancia la teoría de la inexistencia, sin embargo es posible concebir la idea de nulidades virtuales todavía, entendiendo como Cifuentes, nulidades establecidas no de una manera literal sino "que puedan imponerse mediante un razonamiento sobrentendido de su letra y de su espíritu"12, estando más cerca de Falbo, que no cumplan el modelo normativo.

El problema de la teoría de la inexistencia del acto jurídico parte de la su mismo título. Parece un contrasentido hablar de la inexistencia de algo, en relación a algo que exis$t^{13}$, o sea evidentemente tenemos algo en nuestras manos, a lo que se le pretende dar

\footnotetext{
10 CARMINIO CASTAGNO, José Carlos “Inexistencia, invalidez e ineficacia”, Seminario Laureano Moreira Octubre 1995. 11 RIVERA, Julio Cesar, Instituciones de Derecho Civil, Parte General, Ed LexisNexisAbeledoPerrot, 1994 Tomo II, Pag 942. 12 RIVERA, Julio Cesar, Instituciones de Derecho Civil, Parte General, Ed LexisNexisAbeledoPerrot, 1994 Tomo II, Pag 941.

13 Según Wikipedia "El principio de no contradicción, o a veces llamado principio de contradicción, es un principio clásico de la lógica y la filosofía, según el cual una proposición y su negación no pueden ser ambas verdaderas al mismo tiempo y en el mismo sentido. El principio también tiene una versión ontológica: nada puede ser y no ser al mismo tiempo y en el mismo sentido; y una versión doxástica: nadie puede creer al mismo tiempo y en el mismo sentido una proposición y su negación. El principio de no contradicción es, junto con el principio de identidad y el principio del tercero excluido, una de las leyes clásicas del pensamiento lógico"
} 
efectos propios de un acto jurídico pero no lo es. O sea que partimos de tener algo que aparenta ser un acto jurídico. También hay que aclarar que la existencia, si bien pertenece al mundo de lo fenomenológico en cuanto a lo volitivo, se confunde con la existencia jurídica (el valer), ya que el acto jurídico no existe como tal en la naturaleza, sino como una construcción abstracta del ser humano, que lo califica como tal. Así una película tiene un substrato real, pero la calificamos como tal o la diferenciamos de un cortometraje, de un comercial por categorías determinadas por el séptimo arte. Sobre todo en cuanto a lo formal, generalmente nosotros compenetrados en lo jurídico, no se nos pasa por la cabeza una declaración de voluntad por escrito sin la firma, pero no todo el mundo piensa que esto sea necesario. Asi en los instrumentos privados: si lo hizo de su puño y letra... ¿por qué la firma será esencial para su existencia? Y en un instrumento público: Si lo hizo frente a un funcionario fedatario y este así lo asegura.... ¿por qué la firma será esencial para su existencia? Esto solo nos resulta esencial luego de haber estudiado la ley. Hoy es más, podríamos decir en el primer caso, que es un instrumento particular y no un instrumento privado, pero estos nombres no vienen simplemente de la realidad fenomenológica, sino de la realidad jurídica.

Lo que calificamos es la existencia jurídica, que supone una base de existencia fenomenológica con cierta apariencia de acto jurídico, o sea de una declaración de voluntad con fines de crear modificar o extinguir derechos. Sino tenemos esa base fenomenológica que analizar, no tendríamos objeto que analizar, y cuando lo tenemos, no queremos ver si existe en la realidad, porque ya es, sino que queremos saber si produce efectos o no, si la ley se lo permite o no.

El origen etimológico de NULO nos remite al latín "nullus" con el significado de "nada", "nadie" o "ninguno", conformada por el prefijo negativo "nec" y por "ullus" = alguno. Por lo tanto se podría decir que nulo (no alguno) se utilizó para decir que "no es" y por lo tanto podríamos establecerlo como sinónimo de inexistencia. Las palabras nos remiten a lo mismo. Entonces el derecho se encarga de regular este tema, o sea cuando algo "no es" Y lo hace con terminología jurídica, diciendo que es nulo.

Por lo tanto entiendo que no necesitamos recurrir al camino de la teoría de la inexistencia para dejar sin efecto algo que existe y que aparenta ser un acto jurídico y no lo es. Entiendo que no hace falta que la ley literalmente establezca la nulidad en los casos de requisitos esenciales (si en los demás casos), pero estos deben surgir claramente de la ley como tales, y configurar así el modelo normativo. Y lo sano de esta interpretación es que quedándonos en el marco de la nulidad tenemos ya establecida toda la regulación para actuar, me marca quien puede pedir esa falta de efectos, cuando puede pedirlo, etc.

\section{Falta de firma en la Escritura}

Anteriormente el Código de Velez decía:

Art 988 "El instrumento público requiere esencialmente para su validez que esté firmado por todos los interesados que aparezcan como parte en él. Si alguno o algunos de los cointeresados solidarios o meramente mancomunados no lo firmasen, el acto sería de ningún valor para todos los que lo hubiesen firmado"

Art.1004.- Son nulas las escrituras que no tuvieren ...... la firma de las partes, la firma a ruego de ellas cuando no saben o no pueden escribir y la firma de los dos testigos del acto cuando su presencia fuese requerida. La inobservancia de las otras formali- 
dades no anula las escrituras, pero...

Actualmente el CCC dice:

Art 290 "Son requisitos de validez del instrumento público: $a$.... b- las firmas del oficial público, de las partes, y en su caso, de sus representantes; si alguno de ellos no firma por sí mismo o a ruego, el instrumento carece de validez para todos."

Art. 305.- Contenido. La escritura debe contener:

f. la firma de los otorgantes, del escribano y de los testigos si los hubiera; si alguno de los otorgantes no sabe o no puede firmar, debe hacerlo en su nombre otra persona; debe hacerse constar la manifestación sobre la causa del impedimento y la impresión digital del otorgante.

Art, 309.- Nulidad. Son nulas las escrituras que no tengan la designación del tiempo y lugar en que sean hechas, el nombre de los otorgantes, la firma del escribano y de las partes, la firma a ruego de ellas cuando no saben o no pueden escribir y la firma de los dos testigos del acto cuando su presencia sea requerida. La inobservancia de las otras formalidades no anula las escrituras, pero los escribanos o funcionarios públicos pueden ser sancionados.

\section{Terminología del Código}

En ambos códigos, se vuelve a repetir en lo atinente a la escritura, lo que se estableciera en relación a los instrumentos públicos, algo innecesario porque la escritura es una especie dentro del género, parece entonces que el requisito se entiende de mucha importancia. La única diferencia es que en el 305 se habla de firma de los otorgantes y en el 309 vuelve a hablar (como en el 290) de la firmas de las partes.

La terminología empleada en el Código no es del todo precisa. ¿Es lo mismo hablar de parte o de otorgante? ¿Qué entendemos como parte?

Generalmente cuando hablamos de parte entendemos a esta en relación a un negocio jurídico, como aquel que ve afectada su esfera de intereses con el mismo, a diferencia del tercero que está fuera de ese vínculo.

El otorgante en cambio es aquel que "da el negocio jurídico" es un término que se utiliza, tratando de diferenciar al sujeto instrumental del sujeto negocial como lo hace Nuñez Lagos a decir de Herrero Pons ${ }^{14}$. Pero la legislación no contiene una terminología tan depurada, y podemos también llegar a entender el termino "parte" con un doble sentido, como lo hace Lopez de Zavalía que diferencia entre parte formal y parte sustancial, "Parte formal es quien emite la declaración de voluntad. Parte sustancial es el titular de la esfera de intereses que el contrato tiende a regular."15

Por lo tanto podemos decir que el Còdigo utiliza esta terminología en el art 309 haciendo referencia a la parte formal o sea al sujeto instrumental, al sujeto que está presente en la audiencia notarial. Si lo hubiera querido usar solo en el sentido de parte sustancial, tendría que aclarar, como lo hizo el 290, "o en su caso de sus representantes", porque

14 HERRERO PONS, Jorge, “Vademecum notarial”, Ediciones Jurídicas, Bs As 1997, Pág 25

15 LÓPEZ DE ZAVALÍA, Fernando J., Teoría de los contratos. Tomo I Parte General, Bs. As., Zaᄀvalía, 1985, Pág. 290. 
de lo contario toda escritura en la que haya representantes tendrían siempre este vicio de nulidad, pues técnicamente no este firmada por la parte negocial en sentido estricto.

\section{Tres tipos de sujetos intervinientes}

Para buscar un poco más de claridad en este tema podemos decir que hay tres tipos de sujetos intervinientes en una escritura.

El otorgante, es el sujeto como dijimos que da el acto jurídico, crea, genera un vínculo con otro, ya sea personalmente, en nombre propio o en nombre y representación de un tercero. En ambos casos no nos cabe duda que la ausencia de su firma vicia al acto con la nulidad, no solo por lo esencial que es el consentimiento en el aspecto sustancial, sino también en lo formal, puesto que si otorga en nombre propio no quedan dudas que el sujeto es parte (de una u otra manera) y en el caso del representante porque aunque no lo cataloguemos como parte instrumental, el art 290 (más general) prevé expresamente su caso.

En el otro extremo, tenemos a otros sujetos en la audiencia notarial, como es el caso de los testigos que por participar en el instrumento los llamamos sujetos instrumentales, pero a su vez no serían otorgantes del acto jurídico, porque ellos son ajenos al mismo, es más no deben tener interés alguno, testigos que pueden ser los obligatorios (como el caso del testamento) o los que son traídos por otras razones a la realización del instrumento. En este caso la ley también es clara con ellos, su firma no puede faltar, sin viciar con nulidad la escritura.

Por último tenemos otros sujetos que a veces intervienen en una escritura, son los simples presentes, que no son partes negociales, pero que su declaración (a veces conformidad con el acto) está vinculada al acto jurídico instrumentado. La más común de todas, es la presencia del cónyuge prestando el asentimiento conyugal. Pero no es el único caso, también pueden ser los hermanos del comprador cuando hay una venta del padre al hijo, para manifestar su conformidad con la onerosidad del acto. Podríamos mencionar varios casos más. Estos sujetos que participan del instrumento, pero que vamos a evitar llamar por ahora partes instrumentales para no dar ya nuestra posición, sabemos bien que no son parte del negocio, pero tienen una relación con el acto, a veces muy importante (hablando sustancialmente), como en el caso del asentimiento (porque puede causar la nulidad del acto su falta) y otras veces menos importante (como en el segundo caso que deja abierta la posibilidad de una acción de simulación, y luego de colación y reducción).

Aquí, con este último sujeto, se puede plantear la duda con relación a la falta de su firma ¿que consecuencias trae? Pero para analizarlo debemos entender primero que no estamos en el plano de la nulidad sustancial, sino de la nulidad formal. O sea estamos analizando la jarra y no el líquido que contiene, el continente y no el contenido.

\section{Nulidad Formal y Nulidad Sustancial}

Siguiendo a Zinny en este tema diremos que "forma es la manera como el comportamiento se exterioriza, se torna reconocible en la vida de relación. La forma puede consistir en una declaración, una operación o una omisión. Más explícitamente damos forma a nuestros comportamientos: a) hablando (declaración oral), b)escribiendo (declaración escrita), c) manipulando (declaración mediante la computadora), d) gesticulando (declaración del mudo mediante movimientos de la mano, declaración de aceptar la compra 
en subasta inclinando la cabeza, etc) e) operando (edificación, tradición, etc), f) omitiendo hablar, escribir, manipular, gesticular, u operar..."16 Así nos dice el 262 del CCC "Manifestación de la voluntad: Los actos pueden exteriorizarse oralmente, por escrito, por signos inequívocos, o por la ejecución de un hecho material" .

La forma es "el molde en el que la voluntad, sustancia del acto, se vierte y se hace sensible, adquiriendo un sentido mediante el cual los terceros pueden reconocerla, ponderar sus alcances y prever sus consecuencias." ${ }^{17}$ Como bien decía Falbo "El contenido del acto consiste en un pensamiento sin sustrato material. No tiene existencia en el mundo sensible, no vive en el espacio ni en el tiempo.... Lo opuesto ocurre con la forma. Ella en tanto conducta del sujeto pensante que trasmite una idea, necesariamente debe existir en el mundo sensible del aquí y del ahora." ${ }^{18}$ Pero como bien lo aclara "la manifestación escrita, como acción, se produce materialmente en el papel, y que por lo tanto el negocio (como voluntad declarada) se forma en el documento. Por ende, en el documento se constituye el negocio." ${ }^{\prime 19}$ El documento no es prueba que se hace a posteriori del negocio, sino que es la manera en que el negocio paso al mundo de lo fenomenológico. El documento es primordialmente constitutivo y secundariamente probatorio del negocio.

Es muy importante plantear dos ámbitos diferenciados donde se extiende la nulidad del acto jurídico, porque de ellos se derivan consecuencias distintas. Como decía el maestro de mi maestro, o sea el doblemente maestro Moisset de Espanes, hay que distinguir "entre "acto instrumental" y "acto instrumentado", insistiendo en que cuando enfrentamos una escritura pública debemos distinguir "continente" y "contenido", pues en ella hay un acto fruto de la voluntad de las partes (acto instrumentado), que para expresarla recurren al notario que lo dota de una forma (acto instrumental)." ${ }^{20}$

Volviendo al tema anterior, de las faltas de firmas, podemos decir que sustancialmente hay declaraciones de los simples presentes más o menos importantes, y no nos interesa analizar desde este punto de vista su falta que consecuencias acarrea. Estamos mirando al instrumento, al acto desde el punto de vista formal, todos estos simples presentes están en un pie de igualdad entre si y con los otros sujetos que intervienen, son sujetos que el funcionario dice que participan y que firman de conformidad, luego de la lectura y no lo hacen. ¿Qué pasó en la audiencia notarial? ¿Por qué no firmó? Quizas se olvidó el escribano indicarle firmar, quizás no quizo hacerlo, quizás no era cierto que estaba presente, no lo sabemos. Lo que sabemos es que hay una irregularidad, y esta irregularidad tenemos que estudiarla desde la forma.

\section{Interpretación de las normas que la exigen}

En este contexto, el de la forma, como se lleva a cabo ese instrumento, tenemos que ver cual es el sentido de estas normas. Por de pronto analizar que hubiera pasado si no estuvieran. Lo que buscan estas normas (especialmente el art 290) en primer lugar, es proteger a los que signaron el documento antes que otros lo hicieran. Porque hay una

\footnotetext{
16 ZINNY, Mario Antonio, "El Acto Notarial (Dación de fe)" 2Edición, Ed Depalama, Bs As 2000, Pág 13

17 ABELLA Adriana, Código Civil y Comercial. Comentado, anotado, y concordado. Coord Eduardo Gabriel CLUSELLAS, Ed Astrea año 2015, Pág 709 18 FALBO, Marcelo N. "Hacia una depuración de la Teoria de las Nulidades" trabajo presentado en la XXVI Jornada Notarial Argentina, celebrada en Córdoba en el año 2002, pág 9.

19 FALBO, Marcelo N. "Hacia una depuración de la Teoria de las Nulidades" trabajo presentado en la XXVI Jornada Notarial Argentina, celebrada en Córdoba en el año 2002, pág 20.

20 MOISSET DE ESPANES, Luis y Márquez, José F. "Nulidad de escrituras públicas. Responsabilidad del escribano” Revista del notariado no. 897, 112, jul-sep 2009, p. 289-300.
} 
imposibilidad física de que hagamos firmar a todos los sujetos (más cuando son varios) al mismo tiempo. Nadie imagina al notario entregando una lapicera a cada parte y diciendo “preparados, listos ya!!" para solucionar este inconveniente.

Si no existiera esta norma tendríamos solo que analizar quienes firmaron para ver que contratos quedaron realizados. Si en un instrumento se planteara la venta de $A$ a $B$ y de $B$ a $C$, y al momento de firmar solo lo hicieran $A$ y $B$, de no existir esta norma quedarían obligados $A$ y $B$, pero no habría vínculo jurídico entre $B$ y $C$. Pero al existir esta norma, la solución es distinta, si C no firma tampoco hay vínculo entre A y B. La razón es, que al no firmar al mismo tiempo, no se respetaría la voluntad de A y B. Dándole efectos a este instrumento en que no firma $C$, estaríamos burlándonos de la voluntad de $A$ y $B$, ya que lo más probable es que por estar todo en un solo instrumento, seguramente la voluntad de A era contratar con B porque este se vinculaba con C, o sea como condición del negocio; o B se vinculaba con A, solo si C también se vinculaba a él. Esto está explicado en la nota de Velez al 988 donde dice así “El consentimiento dado por las partes signatarias es entendido que es bajo condición de que las partes no signatarias se obligarán también. Si esta condición no se realiza nada se habrá hecho".

Piensen que Vélez habla de "partes signatarias" y en este sentido podemos entender que no hace falta que sean partes sustanciales de un contrato, los artículos se refieren a partes instrumentales, porque lo mismo pasaría con el consentimiento de los firmantes en el supuesto que un simple presente (que supuestamente iba a firmar) no firma prestando su conformidad. Darle entidad a ese instrumento es vapulear duramente la voluntad del sujeto firmante. El ejemplo concreto es ir a comprar un inmueble, se lee la escritura, firma el vendedor, firma el comprador y luego el hermano que decía prestar su conformidad con la onerosidad del acto, no firma. ¿Qué pasa con ese contrato? esto ¿era lo pactado?, pues no, el comprador firmó entendiendo que el hermano firmaría a continuación, sino lo hizo, pues "nada se habrá hecho" (como dice la nota de Velez). No puede obligarse al comprador en estar vinculado en esta situación, o sea, no estamos hablando del derecho del hermano que no firmo a pedir la nulidad, estamos hablando del derecho del comprador a pedirla, establecer que no hay posibilidad de pedir la nulidad en este caso por falta de firma del simple presente, desprotegería al firmante de buena fe, que es lo que busca proteger la norma en principio, pero no solo eso...

Este sentido primero de la norma no agota toda su interpretación, ella también es una de las tantas normas establecidas dentro de las reglas a seguir por este funcionario fedatario, y que hacen al Rito, o sea las formalidades legales o solemnidades.

El rito es el cumplimiento de las formalidades legales o solemnidades, o sea forma como el procedimiento establecido para llegar a la forma (resultado). Toda esa normativa que regula el actuar del notario cuando debe confeccionar el instrumento, que no queda librada al azar, desde que le establece donde realizarlo (Protocolo, Registro de Intervenciones), y específicamente en que lugar de la hoja empezar a escribir(Cabeza de sello), con que tinta trabajar, el idioma que debe utilizar, los elementos de orden que debo consignar (número de escritura, fecha, lugar), como corregir los errores que se hayan realizado, la lectura, la unidad de acto, etc.

"El derecho notarial es, ante todo, un derecho documental que se refiere a una clase de documentos - los autorizados por notarios - y no regula la forma de los contratos sino 
las formalidades o forma procesal procedimiento. "El notario no puede, con su sola intervención, producir el instrumento público; uno por uno, todos sus movimientos están reglados. El notario necesita sujetarse, antes de la firma y después de la firma, a una serie de normas adjetivas, formales, y que en su conjunto definen al derecho notarial como derecho formal, lo que antes que nada quiere decir: Derecho que en sí es todo, colección de formalidades, esto es, forma y procedimiento, FORMA DE LA FORMA y no sólo forma de actos y contratos. La forma de los actos notariales se nos presenta más amplia, y más compleja que la forma del acto jurídico que se contenga en el instrumento. Por otra parte, el mismo Núñez - Lagos enseña que la fe pública, para ser tal exige una fase de solemnidad. El acto de evidencia no tiene fe pública si no se produce en un acto ritual de solemnidad regulado, con más o menos trámites por la ley. Es lo que se llama el rigor formal de la fe pública. La evidencia dentro de la solemnidad, esto es, dentro del conjunto de garantías legales para la fiel percepción, expresión y conservación del hecho histórico". ${ }^{21}$

Justamente y no por casualidad, la génesis del valor probatorio del instrumento público que vemos en el Corpus luris Civiles va de la mano del comienzo de normas que regulan la manera de trabajar del Tabelión en su instrumento “El año 528 puede ser la partida del movimiento ordenante de la notaría. De ese año es la reglamentación justineanea del documento tabeliónico, del cual resultan la preparación de la Schela y la obligación de pasar en limpio in mundum el nogocio o el acto jurídico que abreviadamente se tomaba en la schela... La novela XLIV concertó el modo y la manera de actuar en la statio o plaza, fundando la obligación de prestar el ministerio profesional... No había terminado el 537 cuando se fijaron los requisitos del documento que debía contener el año del imperio, la fecha en que hubiera sido fundada la ciudad donde se extendía el documento, el nombre del consul que gobernaba, la indicación, el mes y el día de instrumentación notarial.."22

Cada norma en cuanto al rito, no es fruto de la casualidad, sino que cada una cristaliza la rica experiencia obtenida a través de los años ${ }^{23}$, para lograr que el Notario pueda percibir con claridad la realidad a plasmar en su instrumento, para que modele el mismo de una manera segura que no de lugar a confusiones, para que quede resguardado el instrumento y perdure esta fuente de verdad por mucho tiempo.

Por todo esto podemos decir que esta Fe Pública no es completamente un salto al vacío del Estado, un depósito de su valor verdad en un sujeto por sus cualidades y prestigio, sino que el Estado trata a través de esa misma legislación de que el camino que tiene este sujeto para decir la verdad, esté regulado de tal manera que no tenga otra posibilidad. Este rito es la garantía para toda la sociedad, puesto que el valor probatorio del instrumento público es erga omnes. Hay que asegurarle al tercero que su fe en ese instrumento no va a ser traicionada. Por lo tanto la norma entendemos también es parte de ese rito y busca proteger la verdad del instrumento que hace plena fe.

\section{Nulidad Absoluta y Nulidad Relativa}

La principal clasificación existente en nuestro ordenamiento legal es la que divide a la nulidad, según si la privación de los efectos se hace en miras a un interés particular o de

21 PELOSI, Carlos A. “El documento Notarial”, $3^{\circ}$ reimpresión, Ed Astrea, Bs As 1997, Pág 179 22 PONDÉ, Eduardo Bautista, “Origen e historia del Notariado", Editorial Depalma, Bs As 1967, Pag 545

23 Por ejemplo cuando en la novela XIV de la obra de Justiniano se establece la unidad de acto, el legislador explica los problemas que se habían suscitado en un caso por no estar presente unos en presencia de otros, durante todo el acto, el conflicto que generaba no poder tener una versión completa de lo que había pasado y que la norma se establecía con esa finalidad 
un interés de la comunidad toda.

Art. 386. Criterio de distinción. Son de nulidad absoluta los actos que contravienen el orden público, la moral o las buenas costumbres. Son de nulidad relativa los actos a los cuales la ley impone esta sanción sólo en protección del interés de ciertas personas.

Decía Pelosi con el anterior código que "la separación entre nulidades absolutas y relativas se basa esencialmente en el interés que resulte perjudicado... La nulidad absoluta se da cuando el interés vulnerado es el social o de orden público... La relativa es la que afecta un interés particular". ${ }^{24}$

Anteriormente el código no era tan claro en el criterio de distinción, se sacaba por interpretación. Por eso era muy necesario el análisis que brindaba la doctrina. Sin embargo hoy, que expresamente lo preceptúa, utiliza una terminología para la absoluta que da lugar a una amplia disquisición, "orden público". "La noción de orden público es variable por las circunstancias de tiempo y espacio. Se han proporcionado explicaciones doctrinarias que no satisfacen. Según Despagnet se refiere al conjunto de reglas que, dadas las ideas particulares admitidas en país determinado, afectan los intereses esenciales de ese país. Para Busso es criterio casi unánime en la doctrina considerar leyes de orden público aquellas que han sido dictadas en el interés de la sociedad, por oposición a las dictadas preferentemente en mira del interés individual." 25 "Pero adviértase que el tipo de ley que rige el caso no basta para calificar la nulidad, pues hay normas de orden público (v.gr. las que se refieren a la incapacidad) que al ser violadas dan lugar a la nulidad relativa, porque en estos casos el derecho protegido es el del incapaz y no el de la sociedad en general." ${ }^{26}$ Como decía Carminio Castagno "Hay "interés general" cuando el bien tutelado excede la esfera individual. Un precepto es de "orden público" si no puede ser modificado por la autonomía privada. En consecuencia, ambas nociones responden a diferentes criterios, combinables y no siempre coincidentes. Así: si bien las normas tuitivas del "interés general" son de orden público, la recíproca no es exacta." 27 Entendemos entonces que el concepto aquí aplicable a orden público no es el más común entendido por la doctrina, sino el que lo establece como en interés de la sociedad toda y hubiera sido mejor hablar de interés general, como se entiende por contraposición a interés individual de la nulidad relativa.

Sin embargo el problema teórico para hablar de una y otra, es poco en relación al problema que se presenta con esta clasificación ante el caso concreto, cuando hay que determinar que busca proteger la ley ante la norma específica, como veremos más adelante.

Si hay algo que no da lugar a dudas, son las consecuencias que se derivan de esta clasificación, cuando estamos en el marco de la nulidad absoluta, ellas son más gravosas, porque no puede sanearse por la confirmación del acto, no prescribe y se permite que más personas puedan plantearlas.

Art. 387. Nulidad absoluta. Consecuencias. La nulidad absoluta puede declararse por

\footnotetext{
24 PELOSI, Carlos A. “El Documento Notarial” Ed. Astrea, 3ºreimpresión Bs As 1997, Pag 293 25 PELOSI, Carlos A. "El Documento Notarial” Ed. Astrea, 3ºreimpresión Bs As 1997, Pag 293

26 MALICKI Anahí Comentario, enCódigo Civil y Comercial de la Nación. Dir: Graciela Medina, Julio C. Rivera. Cord: Mariano Esper. Editorial La Ley 2014. 27 CARMINIO CASTAGNO, José Carlos “Algo más sobre los Actos nulos y anulables”, Revista del Notariado, №854, Pág 51.
} 
el juez, aun sin mediar petición de parte, si es manifiesta en el momento de dictar sentencia. Puede alegarse por el Ministerio Público y por cualquier interesado, excepto por la parte que invoque la propia torpeza para lograr un provecho. No puede sanearse por la confirmación del acto ni por la prescripción.

Consecuencias lógicas, si vemos que la ofensa no es a un sujeto, sino a una comunidad de sujetos, de permitirse la confirmación "subsistiría la relación jurídica generada por el acto y se mantendría viva la ofensa al interés general afectado"28 y por ende la ofensa al resto de los sujetos de esa comunidad, al igual que hacer posible su prescripción "permitiría la confirmación tácita del acto por el transcurso del plazo de prescripción." ${ }^{29}$

Volviendo a nuestro caso, el de la falta de firma de la escritura, tenemos dos motivos o finalidades buscadas por la norma, una en relación a un interés individual de cada uno de los sujetos firmantes, para que tenga vida el documento in totum, o sea todas las declaraciones de los distintos sujetos que intervinieron y no solo alguna de ellas, pues de lo contrario no reflejaría el instrumento la verdadera voluntad cuando firmo el sujeto. Pero por otro lado la norma integra el rito, como garantía de la verdad que impone este documento especial que tiene fe pública, la ley exige la conformidad de los sujetos y no basta que el escribano narre el hecho ocurrido, y desde este punto de vita, esta interpretación de la finalidad de la norma, está protegiendo un interés general de la comunidad toda, que tiene que tener por cierto el hecho. Como dice Falbo de la escritura pública, "no solo es interés de los otorgantes, sino además en protección de los terceros ajenos al negocio. Es la comunidad entera la que necesita asegurar la certeza y autenticidad..." ${ }^{30}$

El problema teórico para hablar de una y otra, es poco en relación al problema que se presenta con esta clasificación ante el caso concreto, cuando hay que determinar que busca proteger la ley ante la norma específica, concepto que muchas veces es revertido teniendo en cuenta las consecuencias para una y otra, lo cual no es correcto. Es una confusión frecuente (generalmente en el estudiante de derecho), tratar de determinar si el vicio causa la nulidad absoluta o relativa a través de sus efectos, o sea determinar primero si es confirmable o no, prescriptible o no, etc y luego establecer entonces si se trata de una nulidad absoluta o relativa. Los efectos o las consecuencias, son segundos en el tiempo, por eso es un error, clasificar el tipo de nulidad en base a ellos.

“Prácticamente, hay acuerdo en la doctrina y jurisprudencia (salvo algunos casos minoritarios), que la falta de firma de algún compareciente, acarrea la nulidad manifiesta y absoluta del instrumento público notarial... Esta nulidad es inconfirmable e imprescriptible para la mayoría de la doctrina, aunque en los últimos tiempos han surgido algunas teorías que intentan ponerle plazo de prescripción o zanjar el problema de otro modo"31 Hay que aclarar que también en general se habla de la firma de los comparentes sin hacer distinción.

Por supuesto que esto es una interpretación, y hay opiniones en contrario una opinión

28 MALICKI Anahí Comentario, enCódigo Civil y Comercial de la Nación. Dir: Graciela Medina, Julio C. Rivera. Cord: Mariano Esper. Editorial La Ley 2014. 29 MALICKI Anahí Comentario, enCódigo Civil y Comercial de la Nación. Dir: Graciela Medina, Julio C. Rivera. Cord: Mariano Esper. Editorial La Ley 2014. 30 FALBO, Marcelo N. "Hacia una depuración de la Teoria de las Nulidades" trabajo presentado en la XXVI Jornada Notarial Argentina, celebrada en Córdoba en el año 2002, pág 21.

31 SIERZ, Susana Violeta, “Derecho Notarial”, Editorial Di Lpalma, Buenos Aires 1988, pág 242 
muy destacada, así en sentido contrario, es la de Lamber $^{32}$ respondiendo a un caso (antes de la reforma del Código) en el que faltó la firma de la cónyuge, diferenció la nulidad sustancial de la formal, pero en lo formal estableció que era una nulidad relativa, por lo tanto subsanable. Traigo a continuación su explicación: “¿Podemos ahora afirmar que se trata de una nulidad absoluta y que como tal es inconfirmable? Sería como la búsqueda de la nulidad por la nulidad misma, borrando cualquier forma de subsanación, cuando lo que debe rescatarse es el acto cuando no produce lesión alguna ni a las partes ni a terceros. "El principio de conservación -dice GATTARI- aquél que los latinos expresaban con el aforismo magisvaleat, quam percal (es preferible que subsista válidamente, y no que perezca), lo cual no deja de ser una aplicación jurídica de aquel principio universal que tienen todos los seres: la existencia". (GATTARI, Carlos N., Manual de Derecho Notarial, pág. 235, Ed. Depalma, Bs As. 1988)... Por ello, aceptarnos como absolutamente legítimo y subsanatorio el acto posterior en que la omitida cónyuge, cuya firma no figura en la escritura matriz a pesar de la manifestación del escribano, viene a declarar, ratificar y otorgar su asentimiento, completando un rasgo material que contradecía a la integridad fedante del documento y que ahora lo deja totalmente subsanado."

Por mi parte vuelvo a insistir en mi opinión, el defecto causa la nulidad absoluta por los intereses en juego, si hubiera una confirmación (nulidad relativa) no debería ser solo del que no firmó el instrumento, sino también del que lo firmó. Pero el vicio causa la nulidad absoluta, es la comunidad la que puede poner en duda la veracidad de ese instrumento que se le pretende imponer como cierto y verdadero, y tiene fundamentos para sospechar, al no haber seguido el rito el escribano como correspondía. La puerta está abierta para que se pida la nulidad y no es la nulidad por la nulidad misma, es la nulidad para protegernos a todos, de actos mentirosos que toman apariencia de verdaderos. Por supuesto que el juez va a evaluar en el caso concreto que determina, va a tener en cuenta valores en juego, y puede no declarar la nulidad, pero esto no significa cambiar la naturaleza del vicio.

\section{Nulos y Anulables}

Esta clasificación, en principio, no ha sido tenido en cuenta en el nuevo código, como estaba presente en el de Velez, que a su vez no los conceptualizaba, pero nos daba ejemplos de unos y otros.

Para esta división, en su mayoría, la doctrina tenía en cuenta "la forma de presentarse el defecto a los ojos del juzgador." ${ }^{33}$ En los actos nulos decía Rivera: "el defecto se presenta al magistrado de modo manifiesto y rígido", lo manifiesto no apuntaba a la ostensibilidad visual sino a la posibilidad del juez de subsumirlo en una hipótesis normativa prevista, no apuntaba a si surgía del documento mismo el defecto, sino que surgiendo del proceso, del expediente, este defecto no cabía dudas era el presupuesto reactivo de la norma que establece la invalidez del acto, sin necesidad de valorar otras circunstancias. A su vez, lo de rígido, hace referencia a que "no es suceptible de grados", se presenta fijo. Por eso la tarea del Juez de valoración es mínima, en estos casos.

Por el contrario en los actos anulables, el defecto no aparece manifiesto a los ojos del juzgador, éste tiene que evaluar y conocer todas las circunstancias que rodean al acto

32 LAMBER, Rubén, “NULIDAD POR FALTA MATERIAL DE FIRMA DE OTORGANTE PRESENTE. SUBSANACION". Cuadernos de Apuntes Notariales $\mathrm{N}^{\circ} 10$, caso $\mathrm{N}^{\circ} 129$

33 RIVERA, Julio Cesar, Instituciones de Derecho Civil, Parte General, Ed LexisNexisAbeledoPerrot, 1994 Tomo II, Pag 942. 
para subsumir el hecho en la norma, porque el hecho es susceptible de grados, o sea puede estar en más o en menos, es flexible y esto le permite al juez determinar si el defecto despierta a la norma o no, en el caso anterior no le permite al juez esta disquisición.

Había críticas a esta clasificación, porque estimaba que "las violaciones de la ley que se fulminan con la invalidez no pueden variar de efectos porque sean visibles o estén ocultas (Galli, Buteler Cáceres, Malicki)"34. Además, aseguraban que aunque la ley decía que los actos anulables se tenían por validos se "confundían los conceptos de invalidez y nulidad, pues tanto el acto nulo como el anulable eran inválidos y en ambos casos, para llegar a la ineficacia, había que impugnar el acto para dar estado a la declaración de nulidad y, también en ambos casos, declarada la nulidad el efecto era retroactivo. De allí, que no era ajustado el texto de los mencionados artículos al decir que el acto anulable es válido o se reputa válido hasta la sentencia que lo anula (art. 1046) y que el acto nulo se reputa tal aunque su nulidad no haya sido juzgada (art. 1038)."135 Además también entiende la doctrina que con la reforma en 1968 del art 1051, quedó prácticamente sin aplicación práctica. Anteriormente por interpretación doctrinaria se circunscribía la protección a los terceros de la declaración de nulidad, solo cuando el acto fuera anulable y no nulo, pasando a proteger al mismo sea el acto nulo o anulable. Por esa razón quedó como única consecuencia, y siempre y cuando se asimile al acto nulo con el de nulidad manifiesta, la posibilidad de la declaración de oficio por el juez cuando hay nulidad absoluta, ("para que proceda la declaración oficio por el juez es preciso que se trate de un acto nulo de nulidad absoluta"36) y aún así hay quienes dicen que carece de todo sentido, como Falbo, puesto que "esa consecuencia no se origina en la característica de la nulidad, sino en la naturaleza de la actuación del Juez... los principios procesales le impiden efectuar investigaciones de hecho, si no le son requeridas a instancia de parte. Luego, la única manera de que el Juez la declare de oficio, será porque la nulidad se le presente espontáneamente frente a sus ojos, independientemente de la consideración de una categoría manifiesta de nulidad"37

Si bien no existe ya esta clasificación desde el punto de vista jurídico no puede "soslayarse que ella tiene entidad ontológica propia y por tanto subsiste plenamente desde el punto de vista fáctico. Es evidente que el vicio que invalida un acto puede a veces estar manifiesto, patente, y otras veces, oculto." ${ }^{\prime 38}$

La falta de firma de una escritura, tornaría al acto en esta clasificación como acto nulo, puesto que sería manifiesto a los ojos del juzgador el vicio, y el vicio no es flexible, no podría tener una consideración de grados, el instrumento tiene la firma o no la tiene, no hay mucho que pensar para subsumir el hecho en la norma. Evidentemente que va a ser más fácil determinar si el acto tiene el defecto o no en los nulos.

\section{Resolución judicial declarativa}

La doctrina moderna se preocupa en distinguir invalidez de nulidad como dos términos distintos, así dice Malicki que "el acto defectuoso (inválido) no es automáticamente

\footnotetext{
34 MALICKI Anahí Comentario, enCódigo Civil y Comercial de la Nación. Dir: Graciela Medina, Julio C. Rivera. Cord: Mariano Esper. Editorial La Ley 2014. 35 MALICKI Anahí Comentario, enCódigo Civil y Comercial de la Nación. Dir: Graciela Medina, Julio C. Rivera. Cord: Mariano Esper. Editorial La Ley 2014. 36 RIVERA, Julio Cesar, Instituciones de Derecho Civil, Parte General, Ed LexisNexisAbeledoPerrot, 1994 Tomo II, Pag 946.

37 FALBO, Marcelo N. "Hacia una depuración de la Teoria de las Nulidades" trabajo presentado en la XXVI Jornada Notarial Argentina, celebrada en Córdoba en el año 2002, pág 20.

38 BITTAR DE DURALDE Amara y MANTEGANI, Silvia "Las enmiendas no salvadas en los instrumentos públicos en el marco del Código Civil y Comercial de la Nación” Revista Notarial No92 (año 2015), Pág 339
} 
ineficaz (nulo); a la causa de la nulidad hay que actuarla. Para pasar de la invalidez a la ineficacia hay un proceso que va del defecto a la impugnación del acto, a la prueba del defecto y a la declaración que da estado a la nulidad". Pareciera entonces que un acto es nulo cuando hay declaración judicial que lo categorice como tal.

Sin embargo cuando estudiábamos la clasificación de actos nulos y anulables, la doctrina decía que era un error pensar que hay actos que se reputan validos (como decía el Código de Velez) hasta la sentencia que declare su nulidad (los anulables) porque en realidad tanto en el código de Velez como en el actual, los efectos de la nulidad son siempre retroactivos, o sea una vez declarada la misma, se equiparan ambos casos, y se deja sin efectos desde el momento mismo del acto y no desde la sentencia. Por lo tanto pensar en un acto con defectos, que da lugar a la ineficacia, como válidos hasta que se declare su nulidad sería un error, son actos nulos, pero que todavía no fueron declarados tales por una sentencia, porque ya tienen el defecto. A lo sumo estaremos en discusión con alguien que lo considere válido.

Entiendo más bien, que esta es una cuestión terminológica, que se trata de imponer para diferenciar al acto defectuoso o que no es tal, con el que es declarado defectuoso o no es declarado como tal. Pero esto no debe implicar ver la sentencia como constitutiva, no es el juez quien la establece, ni siquiera a la ineficacia que ello conlleva, es la ley quien lo hace, el juez solo verifica si realmente hay un desperfecto, como si tuviera que dirimir el conflicto sobre de que color son los tomates, rojo bermellón o rojo carmín, el Juez lo único que hará será decir de que color fue siempre el tomate, y lo más importante imponer las obligaciones que surgen por esa ineficacia, como la de restituir, y volver todo al estado anterior, con la fuerza que le da la misma ley.

Además aún con el anterior régimen que nos permitía reputar a un acto como válido, o como nulo, siempre existió la posibilidad de plantear una controversia en cuento a la nulidad o no de un acto, y en ese caso esta debería dirimirse en sede judicial, tanto para los actos nulos (aún como dice Falbo cuando "la causal fuese patentemente manifiesta, grosera y absoluta"39), como en los anulables en los cuales el defecto no es patente 0 depende de una valoración por el tipo flexible con el que es normado.

El juez, en uno y en otro caso, lo único que hace es verificar si existe el defecto, la falta de un requisito establecido por la ley para la configuración del acto como tal, él solo va a declararlo nulo.

\section{Puede o Debe}

Si bien no tenemos la clasificación en nulos o anulables, para plantear la posibilidad de sentencias constitutivas o no, el nuevo Código Civil y Comercial, ha cambiado la redacción en cuanto a la declaración de nulidad en caso de nulidad absoluta, anteriormente el Código decía art 1047 "La nulidad absoluta puede y debe ser declarada por el juez cuando aparece manifiesta en el acto", hoy el art 387 solo menciona la palabra "puede" dice el artículo en cuestión "La nulidad absoluta puede declararse por el juez, aún sin mediar petición de parte, si es manifiesta en el momento de dictar sentencia". Con lo cual podríamos decir que al ser una facultad del juez declararla o no, su sentencia es constitutiva, dependerá del arbitrio del juez.

39 FALBO, Marcelo N. "Hacia una depuración de la Teoria de las Nulidades" trabajo presentado en la XXVI Jornada Notarial Argentina, celebrada en Córdoba en el año 2002, pág 21. 
Sin embargo no es esa la interpretación que debemos hacer del artículo, la posibilidad hace más hincapié, en relación a que no ha mediado petición de parte, y eso la diferencia de la nulidad relativa, en la que el juez no tiene esa posibilidad, y esto se debe a las características que hemos apuntado anteriormente, que es la protección del interés general.

Parte de la doctrina piensa que esta redacción diferente, fue realizada adrede, pese a no estar esto dicho en los fundamentos, para mostrar que no siempre el juez va a declarar la nulidad del acto, pese a tener el defecto. Dice Falbo: “Es evidente que este cambio no ha sido impensado... Este apartamiento de las fuentes nos permite inferir que en la idea del legislador subyace la posibilidad de considerar que, en ciertos supuestos especiales, es conveniente no declarar la nulidad y mantener la eficacia del acto, en la medida en que se considere que el requisito legal incumplido no alcanza para afectar el interés general ni a afectar la valoración ética que el juez realice, en virtud de circunstancias particulares" ${ }^{\prime 40}$.Pero esto no es necesario remarcar, no hacía falta borrar esa palabra, puesto que siempre el juez debe valorar intereses en juego, y así como no castigaría por robo a quien tomó una manzana por hambre, que pertenecía a otra persona, porque entiende que la vida es un valor superior al de la propiedad privada, también lo hará si hay otros intereses superiores en juego, la misma ley frena a veces los efectos de la nulidad expresamente, como lo hacía el 1051 y lo hace ahora el 392 ante el tercer adquirente a título oneroso y de buena fe, y ya no le deje evaluar si este es un valor superior o no, sino que se lo impone, es taxativo y por lo tanto ese aparente acto jurídico que no es tal, porque tiene un defecto originario, estructural, esencial o importante, va seguir produciendo efectos como uno válido. Lo que sucedía también antes cuando el artículo tenía la palabra debe.

De todas maneras, no implica esto ponernos en la vereda del frente, el juez no puede dejar pasar el no cumplimiento de una norma establecida en interés de toda la comunidad, es su deber, tanto es así que puede hacerlo aunque no haya pedido de parte. Y hacerlo no es simplemente declarar la nulidad por la nulidad misma, sino hacerlo en protección de ciertos valores. Si ese instrumento público está en sede judicial, es porque algún problema hay, y aunque nadie haya planteado el defecto del instrumento como este es uno de los elementos a tener en cuenta en la controversia, el juez puede decidir no contar con él, porque los defectos del rito no le dan la garantía suficiente de contar con la verdad, esa irregularidad, le hace dudar, y si tenemos duda no tenemos fe, el instrumento no sirve, el instrumento no es instrumento público, NO ES o ES NULO.

Vamos nuevamente a nuestro, supuesto, este que nos acompaña para bajarnos un poco a la realidad. La escritura que tiene el juez como uno de los elementos a tener en cuenta en el conflicto judicial, y a la que le falta una firma, tiene un defecto que causa su nulidad, o sea que la ley ha establecido su no valor, pero que de hecho circula en el tráfico comercial como aparente instrumento válido. Puede declararlo nulo, tiene todos los elementos para hacerlo como vimos, pero también puede dejar que siga circulando con la apariencia de tal, si hay otros valores en juego que considera superiores a proteger. Sin perjuicio que más adelante alguien pueda plantear su nulidad, porque no significa tampoco tener cosa juzgada el hecho que haya pasado el instrumento manifiestamente nulo por sede judicial, sin pronunciamiento alguno. 


\section{Declaración en sede notarial}

Dice Rivera "para pasar del acto defectuoso al acto ineficaz (a la nulidad del acto), hay un proceso que va del defecto a la impugnación y de la impugnación a la declaración que da estado a la nulidad. Dicha declaración, según apunta López Olaciregui, puede ser privada o judicial. Es decir que o se ponen de acuerdo en dejar sin efecto el acto (supuesto en el cual los efectos serán los del distracto) o se someten a la justicia." ${ }^{41}$.

Hubo una discusión muy interesante en doctrina, sobre la posible declaración de nulidad en sede notarial de un acto jurídico, entre dos excelentes autores, que vale la pena recordar.

Por un lado Di Castelnuovo concluía en aquel trabajo, que se hizo para un dictamen, que "La declaración posterior de las partes en sede notarial acerca de la nulidad de un contrato es lógicamente posible, jurídicamente válida y resultará plenamente eficaz." ${ }^{42}$

Falbo por su parte disentía de esta posibilidad, diciendo que "Hay un principio rector en materia negocial. Cuando dos personas acuerdan reglar sus derechos, la ley protege esa voluntad asignándole las consecuencias queridas, pero con una importante limitación: ese acuerdo no puede perjudicar a terceros. Ese perjuicio -es decir el trasladar los efectos a un tercero-, que bien puede ser impuesto por la ley, no es potestad de la voluntad de los particulares. Cuando hablamos de nulidad, en cambio, sus consecuencias se extienden a todos los ciudadanos en forma retroactiva. Ahora bien, no cabe ninguna duda de que dos personas pueden por mutuo consentimiento dejar sin efecto las consecuencias queridas de un contrato. De hecho, el art. 1200 lo prevé expresamente. Pero no podrían por mutuo consentimiento establecer que el acto nunca ha existido, extinguiendo sus efectos retroactivamente ${ }^{\prime \prime 4}$.

Por su parte Di Castelnovo entendía que no cabe la posibilidad de rescindir contratos ya concluidos, estando en contra en esto con Solari Costa para quien si se podía. Hay que aclarar que hablaban particularmente de los actos simulados entendiendo Solari Costa que a estos le falta el modo, pero Di Castelnovo entendía que faltaba mucho más que el modo, faltaba el acto. Decía Di Castelnovo "podíamos entender que no se compartiera aquello de que no puede rescindirse lo que "ya fue", pero que nos resultaba sorprendente que pudiera rescindirse lo que "nunca fue" 44 .

A esto contestaba Falbo que si podían hacerlo, y en un dialogo imaginario muy didáctico, hacía ver que aunque el día de mañana un juez dictamine que no podrían haber realizado el distracto de un acto nulo, esta solución ya está dando por sentado que el primer acto es nulo y por consiguiente, este distracto insustancial, no causa nada porque ya al tener por nulo el primero los efectos no se produjeron. ${ }^{45}$

\footnotetext{
41 RIVERA, Julio Cesar, Instituciones de Derecho Civil, Parte General, Ed LexisNexisAbeledoPerrot, 1994 Tomo II, Pag 935. 42 Di Castelnuovo, Gastón R. "Nulidad. Viabilidad de su declaración por las partes en sede notarial”. Revista notarial no. 948, 110, may.ago.04, pp. 320 43 FALBO, Marcelo N. "Declaración de nulidad en sede notarial”. Revista notarial no. 949, 110, sep-dic 04, p. 721-725.

44 Di Castelnuovo, Gastón R. "Nulidad. Viabilidad de su declaración por las partes en sede notarial”. Revista notarial no. 948, 110, may.ago.04, pp. 312 45 FALBO, Marcelo N. "Declaración de nulidad en sede notarial”. Revista notarial no. 949, 110, sep-dic 04, p. 721-725. Por fin, con el antecedente de un acto celebrado, y con la inaptitud para considerar su invalidez, nada impide que de común acuerdo desistan del mismo, extinguiendo las obligaciones y retirando los derechos que se hubiesen producido de acuerdo a derecho. ¿Qué podrían objetar el registrador, un tercer adquirente o, en suma, un juez, ante un futuro conflicto?
} 
Di Castelnovo se resistía a recurrir a los estrado judiciales, cuando no había conflicto que necesitara la lurisdicio. Trayendo en ese momento las palabras de Llambias, para el acto nulo y que como vimos se aplican a toda tipo de nulidad "...La sentencia de nulidad nada innova; no acuerda derechos ni los quita. El aniquilamiento de las consecuencias materiales derivadas del acto nulo no deberá imputarse a la sentencia, que es sólo declarativa de algo preexistente, sino a la ley misma... Con todo, en el orden de los hechos, la sentencia de nulidad es ineludible si se quiere borrar aquellas consecuencias y la otra parte no se aviene a ello"46.

Hay que también que decir que Falbo estuvo en dudas en este tema y así deja en su trabajo un dato muy interesante: la última parte del art. 1200 del Código Civil reza: “Las partes... pueden también por mutuo consentimiento revocar los contratos, por las causas que la ley autoriza". Y su nota concluye afirmando: “... Pero las partes, decimos, pueden revocar los contratos por mutuo consentimiento en los casos que la ley autorice: es decir, si el contrato es hecho por un incapaz, por violencia, dolo, etc., y en tal caso el contrato se juzga no haber tenido lugar...", continuando con la confirmación del concepto y citando a MARCADÉ. De la simple lectura puede afirmarse que, sin dudas, VÉLEZ SARSFIELD aceptó expresamente que la nulidad, aun la relativa, pueda declararse privadamente, con efecto retroactivo y oponible erga omnes, en la medida en que se fundamente en una causal de nulidad prevista en la ley." ${ }^{47}$

Realmente muy interesantes ambos artículos, para leerlos por entero. Ya los había leído muchos años atrás, y quedaron en mi mente dando vueltas y vueltas. Hoy creo poder decir algo al respecto para sumar.

No compartimos la opinión del uso del distracto, hoy la recisión bilateral del art 1076, por varias razones. En primer lugar porque no se puede extinguir lo que no existe, lo que no es, lo que no genera sus efectos propios. En segundo lugar porque suponiendo que este aparente acto jurídico fuera un contrato, no puede darse en los contratos concluidos, o sea cuando las prestaciones principales han sido cumplidas, solo se da en caso que estén pendientes esas obligaciones de lo contrario no hay nada que extinguir. "La doctrina es generalmente acorde en considerar, salvo algunas opiniones contrarias, que la rescisión así comprendida sólo puede concebirse en contratos en vías de cumplimiento, de ejecución continuada o tracto sucesivo, o también en aquellos en donde los efectos no han comenzado aún a producirse" 48

\footnotetext{
Imaginemos este diálogo:

¡Un particular no puede declarar la nulidad! -dirá el juez-

- No lo hemos hecho -contestaríamos-. Por propia voluntad hemos

retrotraído el acto que por propia voluntad habíamos concertado.

- Pero si ese acto era nulo, ¿cómo pretenden retrotraer lo que no ocurrió

-Pues nosotros no podemos afirmar que el acto era nulo; la ley, y con

seguridad su doctrina, nos lo prohíbe.

- Se lo prohíbe a ustedes, particulares, no a mí, y de plano ya mismo

declaro al acto original nulo, $y$ al segundo insustancial.

- Entonces, en ese caso, estamos en el mismo punto al que habíamos llegado nosotros con nuestro distracto, con lo cual su sentencia en nada altera los derechos existentes ni los constituidos con posterioridad. En suma, la sentencia del juez habrá confirmado que el actuar de los particulares se ajustó a procurar -en los límites de sus atribuciones- que la realidad formal coincida con la realidad material, evitando el perjuicio a terceros. En conclusión, no hay impedimento"

46 Di Castelnuovo, Gastón R. "Nulidad. Viabilidad de su declaración por las partes en sede notarial”. Revista notarial no. 948, 110, may.ago.04, pp. 314 47 FALBO, Marcelo N. "Declaración de nulidad en sede notarial". Revista notarial no. 949, 110, sep-dic 04, p. 721-725.

48 ACQUARONE María, COSOLA Sebastián y ROCAN Ricardo. “Código Civil y Comercial de la Nación” Coordinador Eduardo Gabriel CRUSELLAS, Ed Astrea 2015. Pag 834.
} 
Pero dejemos de lado esta postura sobre la rescisión bilateral, y pensemos que aún en contra de nuestras propias ideas, por una cuestión de utilidad, aceptemos usarlo, porque como dice Falbo en cierta manera, es mejor darle a esta declaración de nulidad la forma de rescisión bilateral, para que el Registro por ejemplo tome razón, pues de todas maneras aún que insustancial llegamos a la misma solución que con la declaración de nulidad. Aún así tenemos que ver que la solución sería muchas veces difícilmente aplicable, más si tenemos en consideración que puede darse que el vicio también afecte al mismo distracto por ser este también un contrato. Supongamos un contrato entre cónyuges bajo el régimen de comunidad, nulo por haberlo así establecido el art 1002, como podemos luego hacer su rescisión entre las mismas partes que no podían haber contratado. Estaríamos haciendo un nuevo contrato nulo.

Quiero recalcar que los artículos de ambos autores y sobre todo el de Falbo, tenían en cuenta muy especialmente la opinión del Registro de la propiedad, si iba a aceptar esta declaración en sede notarial para dejar sin efecto el acto o no. Falbo nos contaba el criterio del Registro de la Propiedad que "la nulidad no puede ser juzgada y determinada por los particulares." Sin embargo El artículo $8^{\circ}$ de la ley 17.801 dice: "El registro examinará la legalidad de las formas extrínsecas de los documentos cuya inscripción se solicite, ... a) Rechazará los documentos viciados de nulidad absoluta y manifiesta". O sea sin opinión judicial alguna declara el Registro que el acto está viciado de nulidad, que es inválido, carente de valor, o sea lo está reputándolo NULO, tanto así que no le permite el ingreso. Lo que es de por si toda una contradicción, puesto que si por error le dio cabida y lo registró, no va a permitir tomar razón luego de una declaración particular de las mismas partes que le haga ver la nulidad que no vio en su momento para dejar sin efecto la inscripción.

Cómo puede el Registro, un órgano del Estado sin la luris diccio, establecer que un acto está viciado con nulidad, frenar sus efectos propios como es en el caso lograr la inscripción y sus consecuencias, y por ende truncar la circulación del documento. O sea está actuando de la misma manera que si el acto ya hubiera sido declarado nulo en sede judicial, pero con solo advertir el defecto con cual esta se podría lograr.

Por supuesto que siempre que haya una contradicción en este sentido, o sea si el Registro considera nulo el acto jurídico y el particular lo considera válido, deberán concurrir a la justicia. Pero advirtamos que el procedimiento no es tomar el acto provisionalmente (en este caso) y solicitar la declaración judicial sobre la nulidad del acto para obrar en consecuencia, no... con el solo defecto, lo rechaza.

Pues decimos que no está mal la posibilidad que la ley le otorga al Registro de calificar la validez o nulidad del acto, y actuar en consecuencia. Pues es una posibilidad que tenemos todos los miembros de la comunidad. Si me quieren vender una inmueble adquirido por la venta de un cónyuge a otro, yo también puedo decir que no compro y que lo hago en virtud de la nulidad del acto jurídico que sirve de supuesto título de propiedad.

Muchas veces hemos visto que la nulidad absoluta, es inconfirmable, imprescriptible, y que entonces ante el acto jurídico que tiene este defecto no queda otra solución que la realización de un nuevo acto (reproducción del acto), es más así quedó establecido en 
las XXX Jornada Notarial Argentina llevadas a cabo en Mendoza en el año $2012^{49}$. Ahora ¿necesitamos la declaración judicial de nulidad para la reproducción del acto? Vamos a nuestro caso particular: Leemos la escritura donde hay una venta de $A$ a $B$, con la conformidad de $C$, firma A firma B y C no quiere firmar. ¿Qué hacemos? No autorizamos la escritura y la imprimimos de nuevo con solo el negocio entre A y B. A continuación se firma, y esta si la autorizamos. Tenemos sin embargo un escrito en el protocolo firmado por dos partes intervinientes, que aparenta ser una acto jurídico pero no lo es, a más del defecto de la falta de firma, le hemos agregado la falta de firma del escribano, tiene dos defectos importantes, podríamos decir esenciales. Sin embargo tiene cierta la apariencia de acto jurídico (está hecha en el protocolo, tiene la fecha, etc) y no dudamos en hacer la reproducción del acto a continuación.

Supongamos ahora que hubiéramos firmado por error la escritura anterior, y luego nos percatamos de la falta de firma de C, le solicitamos firmar y no lo hace. ¿Qué hacemos? Pues la misma solución, reproducimos el acto solo entre A y B. En ambos casos hacemos una nota aclaratoria luego de las firmas expresando que esa escritura no pasó por falta de firmas de las partes, que no es ni más ni menos que calificar a este instrumento con un vicio que no le permite ser una escritura.

Pero vayamos más adelante aún, pensemos que hay una escritura así, con la falta de una de las firmas de los sujetos intervinientes, como antecedente, pero de la cual se expidió un testimonio, se inscribió, circuló. ¿Qué hacemos? Pues la solución debería ser la misma porque el defecto es el mismo. Tenemos un aparente acto jurídico que no es tal, porque tiene un defecto originario, estructural y esencial, pero que no permite la confirmación, puesto que los requisitos están establecidos en interés general, porque hace, como vimos, al rito (la ley no solo quiere que declaren ante el escribano, sino que firmen para considerar que está su consentimiento). Debemos hacer la reproducción del acto. Hacer una escritura donde dejo plasmada la conformidad de C, solo hace que se esté en una situación mejor, porque sabemos que él no va a estar interesado en pedir la declaración de nulidad de la escritura, pero los otros si y no solo ellos, también hay otros que la podrían pedirla, aún el juez de oficio. La única solución pues es reproducir el acto.

Ahora, si el acto jurídico de que se trata es título de propiedad, al haber reproducido el acto sin declaración judicial de nulidad, podríamos decir que adquirió B por dos actos distintos. Pero como dice el 1943 “Quien adquiere la cosa por un título, no puede en adelante adquirirla por otro" Sin embargo debemos aclarar que evidentemente el primer acto, aparentaba ser tal y no lo era "no tenía las formas establecidas por ley" como dice el 1892, por lo tanto es tan solo el segundo instrumento el título.

Lógicamente que sería bueno en la reproducción del acto (para lo cual no hay normas específicas) mencionar cual es el acto reproducido (tanto sustancialmente como formalmente) y la causa de su nulidad, como hacemos en una confirmación de una acto con nulidad relativa (que está regulada), pero siempre teniendo en cuenta las diferencias sustanciales que existen, para aplicar la analogía.

49 6) Ante la existencia de una nulidad formal de la escritura, si la voluntad de las partes o sus sucesores es la de sostener la substancia del negocio en ella contenido, el único remedio legal consistirá en la reproducción del acto. 7) Mas allá de las técnicas de redacción de la escritura de reproducción, el único requisito esencial propio consiste en la identidad de partes, o en su caso sucesores, y la voluntad de sostener o reiterar el negocio jurídico celebrado en la escritura que ostentaba la nulidad formal. 8) Siendo la escritura reproducida un acto jurídico autónomo, deben cumplirse los trámites registrales previos y posteriores a su otorgamiento. 9) Las obligaciones impositivas y tributarias cumplidas en la escritura original inválida, en la medida que respondieron a una realidad que materialmente se efectivizó, no deberían exigirse en el acto de reproducción". 
Sin embargo, sino lo hacemos, sino realizamos la conexión, sino hacemos la declaración de la nulidad, como ocurre generalmente al reproducir inmediatamente el acto no se traduce esto en un inconveniente. Es importante sobre todo cuando ha pasado un tiempo ya, o ha circulado el aparente acto. Pero de todas maneras siempre pensando que lo verdaderamente importante aquí no es la declaración de nulidad, sino la existencia de un acto válido con el cual contar.

La diferencia es que nuestro actuar, en todos estos casos, es pensando la solución, para que todo siga como el acto aparente pretendía. Y en estos casos estamos dando por obvia la declaración de nulidad, para hacer el verdadero acto. El mismo Registro tampoco la pide, y la da por sobreentendida.

Pero si no se puede reproducir el acto porque justamente la ley marca la imposibilidad de hacerlo con esas mismas partes, ¿cómo se hace para dar marcha atrás?. No puedo reproducir el acto, solo queda la declaración de nulidad.

Por supuesto que esta declaración particular de nulidad, que cuando hacemos la reproducción del acto, la damos por sobreentendida, no podrá perjudicar a terceros, y si los hubiere deberá realizarse judicialmente.

Aquí también será útil la antigua clasificación en actos nulos y anulables, puesto que la prudencia, propia de todo notario, indica restringir esta declaración a los primeros solamente, donde no entra la duda, donde el defecto es evidente y no es una cuestión de apreciación en grados.

Lo importante es entender que la nulidad del acto está dada por el defecto que contiene. La declaración judicial de nulidad, es solo declarativa. Es la ley la que priva al acto de los efectos propios, retroactivamente en todos los casos.

Todos tenemos el derecho de reputar al acto como nulo o válido, y solo si da lugar al conflicto en esto, será necesario la declaración judicial de nulidad.

\section{Conclusiones}

1) No necesitamos recurrir al camino de la teoría de la inexistencia para dejar sin efecto algo que existe y que aparenta ser un acto jurídico y no lo es. Lo sano de esta interpretación es que quedándonos en el marco de la nulidad tenemos ya establecida toda la regulación para actuar.

2) No hace falta que la ley literalmente establezca la nulidad en los casos de requisitos esenciales (si en los demás casos), pero estos deben surgir claramente de la ley como tales, y configurar así el modelo normativo.

3) Hay dos ámbitos bien diferenciados donde se extiende la nulidad del acto jurídico, y por eso podemos diferenciar Nulidad Formal y Nulidad Sustancial.

4) Las nulidades formales, establecidas para la realización de la Escritura pública, dan lugar siempre a la Nulidad Absoluta, por ser normas que integran el rito, o sea las solemnidades que se han establecido como garantía para asegurarle a la comunidad que su fe 
en ese instrumento no va a ser traicionada.

5) La sentencia que da lugar al estado de nulidad es declarativa. Los efectos de la nulidad son siempre retroactivos.

6) Pensar en un acto con defectos, que da lugar a la ineficacia, como válido hasta que se declare su nulidad es un error, son actos nulos (porque ya tienen el defecto), pero que todavía no fueron declarados tales por una sentencia.

7) Es posible la declaración de nulidad en sede notarial de los actos nulos (tomando la antigua clasificación). No solo para la reproducción del acto jurídico.

\section{BIBLIOGRAFÍA}

- MALICKI Anahí Comentario, en Código Civil y Comercial de la Nación. Dir: Graciela Medina, Julio C. Rivera. Cord: Mariano Esper. Editorial La Ley 2014.

- RIVERA, Julio Cesar, Instituciones de Derecho Civil, Parte General, Ed LexisNexisAbeledoPerrot, 1994 Tomo II.

- FALBO, Marcelo N. "Hacia una depuración de la Teoria de las Nulidades" trabajo presentado en la XXVI Jornada Notarial Argentina, celebrada en Córdoba en el año 2002, pág 20.

- FALBO, Marcelo N. “Código Civil y Comercial de la Nación” Coordinador Eduardo Gabriel CRUSELLAS, Ed Astrea 2015.

- ZAVALA, Gastón Augusto, "Ineficacia y subsanaciones en el documento notarial”, Revista Notarial N943, Pag 758 Año 2002.

- CARMINIO CASTAGNO, José Carlos "Inexistencia, invalidez e ineficacia”, Seminario Laureano Moreira Octubre 1995

- CARMINIO CASTAGNO, José Carlos "Algo más sobre los Actos nulos y anulables", Revista del Notariado, N854, Pág 51.

- HERRERO PONS, Jorge, "Vademecum notarial", Ediciones Jurídicas, Bs As 1997, Pág 25

- LÓPEZ DE ZAVALÍA, Fernando J., Teoría de los contratos. Tomo I Parte General, Bs. As., Zavalía, 1985, Pág. 290.

- ZINNY, Mario Antonio, “El Acto Notarial (Dación de fe)" 2Edición, Ed Depalama, Bs As 2000, Pág 13

- ABELLA Adriana, Código Civil y Comercial. Comentado, anotado, y concordado. Coord Eduardo Gabriel CLUSELLAS, Ed Astrea año 2015, Pág 709

- MOISSET DE ESPANES, Luis y Márquez, José F. “Nulidad de escrituras públicas. Responsabilidad del escribano" Revista del notariado no. 897, 112, jul-sep 2009, p. 289-300.

- PELOSI, Carlos A. “El documento Notarial", $3^{\circ}$ reimpresión, Ed Astrea, Bs As 1997, Pág 179

- PONDÉ, Eduardo Bautista, "Origen e historia del Notariado", Editorial Depalma, Bs As 1967, Pag 545

- SIERZ, Susana Violeta, “Derecho Notarial”, Editorial Di Lpalma, Buenos Aires 1988, pág 242

- LAMBER, Rubén, "NULIDAD POR FALTA MATERIAL DE FIRMA DE OTORGANTE PRESENTE. SUBSANACION". Cuadernos de Apuntes Notariales No 10, caso №129

- BITTAR DE DURALDE Amara y MANTEGANI, Silvia "Las enmiendas no salvadas en los 
instrumentos públicos en el marco del Código Civil y Comercial de la Nación" Revista Notarial N92 (año 2015), Pág 339

- FALBO, Marcelo N. "Declaración de nulidad en sede notarial". Revista notarial no. 949, 110, sep-dic 04, p. 721-725.

- DI CASTELNUOVO, Gastón R. “Nulidad. Viabilidad de su declaración por las partes en sede notarial". Revista notarial no. 948, 110, may.ago.04, pp. 312 
